\title{
Electrodeposition of Fe-Sn from the chloride-based electrolyte
}

Simona Mrkonjić Zajkoska*1,2, Rudolf Mann ${ }^{1}$, Wolfgang Hansal*1, Sudipta Roy ${ }^{3}$, Wolfgang Kautek ${ }^{2}$

${ }^{1}$ Hirtenberger Engineered Surfaces GmbH, Hirtenberg, Austria

${ }^{2}$ Department of Physical Chemistry, University of Vienna, Vienna, Austria

${ }^{3}$ Chemical and Process Engineering Department, University of Strathclyde, Glasgow, United Kingdom

Corresponding authors: simona.zajkoska@hirtenberger.com,

wolfgang.hansal@hirtenberger.com 


\section{Electrodeposition of Fe-Sn alloys from a chloride-based electrolyte}

The conditions for electrodeposition of Fe-Sn alloys from a novel, environmentally friendly, ferrous chloride-based electrolyte were studied. The influence of the $\mathrm{pH}$ on the electrolyte stability and deposit stoichiometry was discussed. Anodic stripping voltammetry (ASV), XRD and SEM/EDX were used to characterize the electrodeposited phases. The results from ASVs indicated the possibility to deposit at least two different phases at high overpotentials. Hull cell depositions in an electrolyte with a $\mathrm{Sn}$ to $\mathrm{Fe}$ ratio 1:1 and a $\mathrm{pH}$ value of 2.8 showed regular deposition of Fe-Sn. Fe-rich deposits (54.84 at \%) were obtained from an electrolyte with $\mathrm{Sn}$ to Fe ratio 1:10. The XRD results were compatible with the electrochemical investigations. In all studied samples $\beta-\mathrm{Sn}, \mathrm{FeSn}_{2}$ and $\mathrm{Fe}_{5} \mathrm{Sn}_{3}$ were detected. The presence of ferromagnetic $\mathrm{Fe}_{5} \mathrm{Sn}_{3}$ was not influenced by the $\mathrm{Sn}$ to $\mathrm{Fe}$ ions ratio in the electrolyte.

Keywords: tin-iron electrodeposition; ferrous-stannous electrolyte; anodic stipping voltammetry; Hull cell; chloride; XRD

\section{Introduction}

Nowadays, the alloys used most frequently for magnetic materials are iron based with nickel and cobalt [1]. However, $\mathrm{Ni}$ is highly allergenic and $\mathrm{Co}(\mathrm{II})$ salts are carcinogenic and materials of very high concern according to European Chemicals Agency [2]. Fe-Sn alloys are a potential alternative to these classical magnetic materials. In the binary thermal equilibrium diagram of $\mathrm{Fe}-\mathrm{Sn}$ five intermetallic compounds are found, namely: $\mathrm{FeSn}_{2}, \mathrm{FeSn}, \mathrm{Fe}_{3} \mathrm{Sn}_{2}, \mathrm{Fe}_{5} \mathrm{Sn}_{3}$ and $\mathrm{Fe}_{3} \mathrm{Sn}$ [3]. The iron-rich compounds $\mathrm{Fe}_{3} \mathrm{Sn}_{2}, \mathrm{Fe}_{5} \mathrm{Sn}_{3}$ and $\mathrm{Fe}_{3} \mathrm{Sn}$ are ferromagnetic [3] and, due to their low cost and low harm to health and environment, interesting for industrial usage. Possible applications of the Fe-Sn alloy deposits are magnetic recording [4,5] or corrosion protection coatings [6]. Different Fe-Sn phases were obtained by mechanical milling [7], alloying [8] or cosputtering [9,10]. Literature research showed almost no records in the field of 
electrodeposition of Fe-Sn [11].

In our previous research we were studying the mechanism of electrodeposition of Fe-Sn from ferric salts and tartrate as a single complexing agent [12]. However, the electrochemical equivalent of $\mathrm{Fe}^{3+}$ is lower than the one of $\mathrm{Fe}^{2+}$. Therefore, in the present study, the conditions for Fe-Sn electrodeposition from a ferrous, chloride based electrolyte are discussed. Influence of the $\mathrm{pH}$ and $\mathrm{Sn}-\mathrm{Fe}$ ion ratio in the electrolyte on the deposit morphology and stoichiometry is described. Anodic stripping was used to characterize the possible electrodeposited phases of Fe-Sn. In all the deposited samples a ferromagnetic $\mathrm{Fe}_{5} \mathrm{Sn}_{3}$ was detected.

\section{Materials and Methods}

The conditions of co-deposition of $\mathrm{Fe}-\mathrm{Sn}$ were studied in a chloride-based electrolyte ( 
Table 1). Electrochemical experiments were carried out in a standard $300 \mathrm{ml}$ electrochemical cell with a three electrodes setup. The working electrode was a gold tipped rotating disc electrode ( $\mathrm{RDE}, 0.1 \mathrm{~cm}$ radius). A platinum wire was used as a counter electrode. A saturated calomel electrode (SCE), connected via a Luggin capillary, was used as a reference electrode. In the text all the potentials were recalculated to the standard hydrogen electrode (SHE) as a reference. The electrolyte temperature was kept constant at $60^{\circ} \mathrm{C}$ with a water bath. All the experiments were carried out using an $\mu$ Autolab II (Metrohm) potentiostat, controlled with the NOVA 2.0 software. The surface of the RDE was wet polished with 4000 grid silicon paper and washed with DI water before each experiment. Electrolyte $\mathrm{pH}$ was adjusted with $10 \% \mathrm{H}_{2} \mathrm{SO}_{4}$. 
Table 1: Electrolyte composition. Metal ion concentration $(\mathrm{Sn}+\mathrm{Fe})$ was kept constant at $0.11 \mathrm{M}$ with different $\mathrm{Sn}: \mathrm{Fe}$ ion ratio.

\begin{tabular}{ll}
\hline 3Na citrate x $2 \mathrm{H}_{2} \mathrm{O}$ (Sigma Aldrich) & $0.27 \mathrm{M}$ \\
$\mathrm{KNa}$ tartrate x $4 \mathrm{H}_{2} \mathrm{O}$ (Sigma Aldrich) & $0.09 \mathrm{M}$ \\
$\left(\mathrm{NH}_{4}\right)_{2} \mathrm{SO}_{4}$ (Sigma Aldrich) & $0.45 \mathrm{M}$ \\
$\mathrm{SnCl}_{2} \times 2 \mathrm{H}_{2} \mathrm{O}$ (Sigma Aldrich) & \\
$\mathrm{FeCl}_{2} \mathrm{X} 4 \mathrm{H}_{2} \mathrm{O}$ (Alfa Aesar) \\
\hline
\end{tabular}

The deposition potential of Sn was measured from an electrolyte containing only 0.11 M of Sn as an electroactive substance. Polarization measurements for this electrolyte were performed on a static RDE with a scan rate of $5 \mathrm{mV} / \mathrm{s}$, starting at the OCP and continued into the cathodic direction until $-1.25 \mathrm{~V}$ vs. SHE. Anodic stripping voltammograms (ASVs) in the single metal Sn electrolyte were carried out at the $\mathrm{pH}$ value that has been present in the electrolyte initially and it has not been further adjusted.

The deposition potential of $\mathrm{Fe}$ in a chloride-based electrolyte was determined in an electrolyte containing $0.11 \mathrm{M}$ of $\mathrm{Fe}$ as an electroactive species. Since hydrogen evolution is a significant side reaction of Fe deposition, the reduction potential of Fe could not be determined directly. For this purpose, a series of ASVs with the scan rate of 30 $\mathrm{mV} / \mathrm{s}$ were carried out. Fe was electrodeposited during the cathodic polarisation sweep. The cathodic reverse potential was varied from $-0.35 \mathrm{~V}$ to $-1.25 \mathrm{~V}$ vs. SHE with the step of $-0.1 \mathrm{~V}$. . The appearance of the Fe anodic stripping peak indicated the position of the Fe reduction potential. The measurements were first carried out in an electrolyte with non-adjusted $\mathrm{pH}$ with the value of 6.0 and afterwards at a $\mathrm{pH}$ of 2.8 . 
Anodic stripping voltammetry as an in-situ technique for characterization of electrodeposited Fe-Sn layers was used. Electrodeposition of the layers was performed via cathodic polarization of the stationary, gold disc electrode. Electrolytes with $\mathrm{Sn}$ to Fe ratio $1: 1,1: 3$ and $1: 10$ were tested at the $\mathrm{pH}$ of 2.8 . In the electrolyte with $\mathrm{Sn}$ to Fe ratio 1:3 the cathodic potential was changed from $-0.95,-1.05$ to $-1.25 \mathrm{~V}$. Current density transients were recorded on a gold tipped RDE at the potential $-0.75 \mathrm{~V}$ vs SHE with 100 rpm for $300 \mathrm{~s}$.

The metal speciation was calculated in Visual MINTEQ 3.1 [13]. The oxidation of $\mathrm{Fe}^{2+}$ to $\mathrm{Fe}^{3+}$ was not considered in the chemical equilibrium modelling. Consequently, Hyperquad Simulation and Speciation (HySS) software [14] was used for the calculation of species' concentration and visualization.

Galvanostatic Fe-Sn deposits were obtained from Hull cell experiments which were carried out in a standard $267 \mathrm{ml}$ cell (Kocour). A constant current of $1 \mathrm{~A}$ was applied for 10 minutes on a brass substrate. For this purpose, electrolytes ( $\mathrm{pH} 2.8$ ) with $\mathrm{Sn}$ to Fe ion ratios 1:1 and 1:10 were prepared. Attempts to achieve smoother deposits from the Sn:Fe electrolyte 1:10 were made by adding $1.6 \mathrm{mg} / 1$ of alkoxylated $\beta$-napthol [15] $(\mathrm{ABN})$. The electrodeposited dendrites were collected on a double side adhesive carbon tape and investigated with SEM/EDX. In order to study the phase composition and overall stoichiometry of the compact underlying layer, the dendrites were mechanically removed by rubbing with an isopropanol wetted cotton pad. The SEM/EDX investigation was performed on the $1 \mathrm{x} 1 \mathrm{~cm}$ sample cut along the $40 \mathrm{~mA} / \mathrm{cm}^{2}$ zone of the Hull cell electrode. In the nominal current densities the SEM/EDX samples were cut between 33.78 and 48.44 $\mathrm{mAcm}^{-2}[16]$

The surface topography and the deposit stoichiometry were analysed with the scanning electron microscope (SEM) Hitachi S-4800 equipped with an energy dispersive 
X-ray detector (EDX). The phase composition of the deposits was studied with an X-ray diffractometer Empyrean PANalytical using a grazing incidence geometry. The samples were scanned at $10-100^{\circ} 2 \theta$ with $\mathrm{CuK} \alpha$ radiation and the incidence angle of $2^{\circ}$. The scanning step of the scintillation detector with a long plate collimator was $0.02^{\circ}$.

\section{Results and discusion}

Polarization curves in the tin electrolyte are depicted for various $\mathrm{pH}$ values (Figure 1). A significant cathodic shift of the tin reduction potential from approximately $-0.28 \mathrm{~V}$ to $-0.54 \mathrm{~V}$ with a change of $\mathrm{pH}$ from 2.2 to 8.0 was observed. According to the Nernst equation, a possible explanation could be either the change of the metal-complex character or the increase of the tin-complexes stability [17]. Simulation of the electrolyte speciation (Figure 2a) showed a changed distribution of Sn complexes in this $\mathrm{pH}$ region. In the weak acidic and neutral region, within the $\mathrm{pH}$ values of 4.0 and $7.0, \mathrm{Sn}$ is mostly deposited from the $\left[\operatorname{Sn}(\operatorname{tart})_{2}\right]^{2+}$ complex. The observed shift in the Sn deposition potential in this $\mathrm{pH}$ region is caused by the increased stability of the $\left[\mathrm{Sn}(\operatorname{tart})_{2}\right]^{2+}$ complex [12]. On the other hand, in the more acidic $\mathrm{pH}$ region ( $\mathrm{pH}$ values from 2.0 to 4.0 ), $\mathrm{Sn}$ is present in form of different complexes, such as $\left[\mathrm{Sn}(\operatorname{tart})_{2}\right]^{2+},[\mathrm{Sn}(\operatorname{tart})],[\mathrm{SnCl}]^{+}$or $\left[\mathrm{SnCl}_{2}\right]$. The shift of the Sn reduction potential in this case is caused by the change of the concentrations of the various Sn complexes.

The anodic stripping voltammetries (ASV) were measured in the single metal Sn electrolyte with two different cathodic return potentials $(-0.75 \mathrm{~V}$ and $-1.25 \mathrm{~V})$ at the initial electrolytes' $\mathrm{pH}$ with the value of 5.2 (Figure 3). For both return potentials, three stripping peaks ( $A, B$ and $C$ ) were observed. The peak $C$ can be assigned to the passivation of $\mathrm{Sn}$ $[18,19]$, peak $B$ refers to the oxidation of Sn and thus its height depends on the amount of the reduced Sn [15]. The consecutive shoulder can be explained by the higher amount of 
reduced $\mathrm{Sn}$ at the return potential of $-1.25 \mathrm{~V}$ in comparison to the amount of $\mathrm{Sn}$ reduced at return potential of $-0.75 \mathrm{~V}$.

The Fe reduction potential was determined from the ASVs by changing the cathodic reverse potential (Figure 4). ASVs were performed in electrolytes with the $\mathrm{pH}$ values of 6.0 and 2.8. In the anodic branch, two peaks ( $D$ and $E$ ). were observed. The stripping peak $D$ was detected, for the first time, in both $\mathrm{pH}$ values, when the electrode was polarized cathodically up to $-0.85 \mathrm{~V}$ vs SHE. No striping peak was detected with the cathodic return point of $-0.75 \mathrm{~V}$, which indicates, that the reduction potential of Fe lies $\begin{array}{lllllll}\text { between } & -0.75 & \text { and } & -0.85 & \mathrm{~V} & \text { vs } & \text { SHE }\end{array}$ (Figure 4). The potential of the peak $D$ was shifted towards more positive values with the decrease of the electrolyte $\mathrm{pH}$. Although the electrolyte speciation does not consider the possibility of oxidation of $\mathrm{Fe}^{2+}$ to $\mathrm{Fe}^{3+}$, it can indicate a possible mechanisms of $\mathrm{Fe}^{2+}$ reduction (Figure $2 \mathrm{~b}$ ). At the $\mathrm{pH}$ value of 6.0 , most of the $\mathrm{Fe}^{2+}$ ions should be present in the form of the $[\mathrm{Fe}(\mathrm{citr})]^{-}$complex with the stability constant of 5.89 [14]. On the other hand, at the $\mathrm{pH}$ value of $2.8, \mathrm{Fe}$ is predominantly reduced from the $\left[\mathrm{Fe}\left(\mathrm{SO}_{4}\right)\right](\operatorname{logK}=2.8)$ and $[\mathrm{FeH}(\mathrm{citr})]$ with the stability constant, $\operatorname{logK}$ of 10.17 [14]. Therefore, it can be assumed, that the observed shift in the stripping peak $D$ at the $\mathrm{pH}$ of 2.8 , can be result of oxidation of $\mathrm{Fe}$ to $[\mathrm{FeH}(\mathrm{citr})]$. Additionally, the peak $E$ around $+0.2 \mathrm{~V}$ was observed in single Fe electrolyte at the $\mathrm{pH}$ value of 6.0. Similar to peak $\mathrm{E}$, the stripping peak $A$ was detected in the single Sn electrolyte at the $\mathrm{pH}$ value of 5.2 (Figure 3). Analogous to the Fe stripping peak $D$, the potential of $E$ was shifted towards more positive values when the electrolyte $\mathrm{pH}$ decreased to 2.8 (Figure 4). In our previous work [12] we have studied the mechanism of Fe-Sn electrodeposition from a similar electrolyte with tartrate as the single complexing agent. In the $\mathrm{AVs}$ of $\mathrm{Fe}$, no additional stripping peaks such as $E$ were observed. Moreover, the supporting electrolyte [12] did not have any anodic response. 
This leads us to the assumption, that the origin of the peaks $A$ and $E$ could be in the oxidation of a citrate related species (Figure $2 \mathrm{~d}$ ). However, for better understanding of the origin of stripping peaks $A$ and $E$, more detailed analyses have to be performed.

For an alloy deposition of two different metals to occur, the difference between their standard reduction potentials $E_{0}$ should be less than $0.2 \mathrm{~V}$ [20]. If the alloy deposition of two metals is not possible, there is a need to shift their reduction potentials towards each other. Most common methods for bringing together two different reduction potentials are: changing the concentration of one of the metal species and thus altering its activity; changing the character and stability constants of the metal complexes; and usage of the selective surface active additives, which can increase the reduction overpotential of the more noble metal [20]. In the case of $\mathrm{Sn}^{2+}$ and $\mathrm{Fe}^{2+}$, the difference between standard reduction potentials $E_{0}$ is $-0.3 \mathrm{~V}$ [21]. A similar difference in the reduction potentials of Sn and Fe was estimated from the single metal electrolytes at the initial $\mathrm{pH}$. For $\mathrm{Sn}$ at the $\mathrm{pH}$ of 5.2 the reduction potential was estimated to be around $-0.45 \mathrm{~V}$ (Figure 1). For Fe the reduction potential at the initial electrolyte $\mathrm{pH}$ value of 6.0 was located between -0.75 and $-0.85 \mathrm{~V}$ (Figure 4). The reduction potential of $\mathrm{Sn}$ at the lower $\mathrm{pH}$ is shifted towards more positives values (Figure 1) and with that, the difference between the reduction potentials of $\mathrm{Fe}$ and $\mathrm{Sn}$ is increasing. For this reason, the mixed Fe-Sn electrolyte with $\mathrm{Fe}$ to $\mathrm{Sn}$ ratio of 1:1 at the initial, non-adjusted $\mathrm{pH}$ value of 5.5 was chosen as optimal for Fe-Sn electrodeposition. Nevertheless, the mixed Fe-Sn electrolyte ( $\mathrm{pH}$-5.5) was changing the colour over time from light-yellow to orange-brownish, indicating the instability of the electrolyte. The current density transients were decreasing with every repetition. The value of the current density after $100 \mathrm{~s}$ of electrodeposition has changed from approximately $-25 \mathrm{mAcm}^{-2}$ at the first into half of its value in the third repetition (Figure $5 \mathrm{a}$ ). After $300 \mathrm{~s}$ of electrodeposition, the difference between the measured current 
density in the first and the third repetition was one order of magnitude. Such massive changes in the current density after each experiment are confirming the instability of the electrolyte. The change of the electrolyte colour as well as its instability can be related to the oxidation of the ferrous ion and the creation of ferric hydroxide species [22,23]. Formation of hydroxides results in a reduced concentration of electroactive metal species and therefore also to the decrease of current density (Figure 5 a).

In order to suppress the oxidation of $\mathrm{Fe}^{2+}$ and the formation of hydroxides, the $\mathrm{pH}$ of the supporting electrolyte was adjusted to a value of around 3 before adding the Fe and Sn salts. This method of electrolyte preparation resulted in a Fe-Sn electrolyte with a Fe to $\mathrm{Sn}$ ratio of 1:1 at a $\mathrm{pH}$ of around 2.8. The colour of the electrolyte was light-green and did not change over time. The chronoamperometry results were reproducible(Figure 5). After $100 \mathrm{~s}$ of electrodeposition at $-0.75 \mathrm{~V}$, the recorded current densities were about $200 \mathrm{mAcm}^{-2}$, which is an order of magnitude higher than in the first measurement at the $\mathrm{pH}$ of 5.5 (Figure 5). The steep decrease in the recorded current densities over time indicates that the deposition at these conditions is not kinetically controlled and leads to a significant increase of the electrode's active area. Moreover, an increase in noise indicates a massive hydrogen evolution (Figure $5 \mathrm{~b}$ ).

The change of the Fe-Sn (metal ion ratio of 1:1) electrolyte $\mathrm{pH}$ to 2.8 leads to an increase of its stability. On the other hand, it also causes the difference of the reduction potentials of Fe and $\mathrm{Sn}$ to increase to more than $-0.4 \mathrm{~V}$ (Figure 1, Figure 4). In order to bring the reduction potentials closer together, the concentration of the more noble metal Sn was reduced. Electrolytes with $\mathrm{Sn}$ to Fe ratio of 1:1, 1:3 and 1:10 were tested. In these electrolytes, ASVs with different cathodic reverse potentials were performed in order to analyse the electrodeposited phases (Figure 6, Figure 7) and to determine the influence of the metal ion ratio in the electrolyte on the resulting electrodeposits. In the 
thermodynamic phase diagram of Fe-Sn [3], in addition to the Sn phase and the solid solution of Fe-Sn, five intermetallic phases are found. Therefore, in ASVs, several stripping peaks were expected to be observed. The results of the ASVs with a cathodic polarization up to $-1.25 \mathrm{~V}$ are depicted in Figure 6. Three stripping peaks (I, II, and III) were observed, independent of the electrolyte composition. Additionally, a small peak at the potential $\sim 0.2 \mathrm{~V}$ was observed in all studied electrolyte compositions (Figure 6, Figure 7). Such a peak was also detected in the single Sn (peak $A$, Figure 3 ) and Fe (peak $E$, Figure 4) electrolytes. As it was already discussed above, the origin of this peak might be related to the oxidation of the citrate complexes, such as $\left[\mathrm{H}_{3}(\mathrm{citr})\right],\left[\mathrm{H}_{2}(\mathrm{citr})\right]^{-}$or $[\mathrm{H}(\mathrm{citr})]^{2-}$ (Figure 2 Figure 2 d). Therefore, this peak was not considered to be significant in the stripping analyses of Fe-Sn and will be a subject of further investigation. The peak heights of I, II and III depended on the metal ion ratios in the electrolyte. The peaks II and III were reduced in size with the decreased amount of Sn ions in the electrolyte. On the other hand, the height of peak I increased with higher concentrations of Fe ions (Figure 6). The peak $\mathrm{Nr}$ I $(\sim-0.4 \mathrm{~V})$ appeared for the first time when the potential in the cathodic polarization reached $-1.05 \mathrm{~V}$ vs SHE (Figure 7) and it was in good correlation to the stripping peak of Fe (Figure 6). This indicates that the peak Nr. I is probably related to the reduction of a Fe or Fe-rich intermetallic phase [24]. If both of the metals do not passivate in the investigated electrolyte, each stripping peak indicates a different intermetallic, intermediate or compound dissolution[24]. In the case of Fe, at the $\mathrm{pH}$ of 2.8, no passivation was observed (Figure 4). For $\mathrm{Sn}$ in the acidic citrate buffers ( $\mathrm{pH} 3$ and 4 ) a single anodic peak was observed, but it was also shown that it undergoes active dissolution-passivation process [25]. Therefore, it can be assumed that the three stripping peaks (I, II and III, Figure 6, Figure 7) belong to at least two different phases with the possibility, that one of them is a Fe or Fe-rich intermetallic phase $[24,26]$. 
A fast and an efficient way to perform electrodeposition with a range of current densities at once is a Hull cell. (Figure 8). Electrolytes with $\mathrm{Sn}$ to Fe ratio of 1:1 and 1:10 were selected for these experiments. In the case of the Sn-Fe electrolyte with an 1:1 metal ratio, massive grey dendrites were present over the whole current density range of the Hull cell (0.4- $\left.40 \mathrm{mAcm}^{-2}\right)$ (Figure 8). The tree-like structure of the dendrites (Figure 9) indicates a fully diffusion controlled deposition [27]. With the increase of the Fe content in the electrolyte the morphology of the deposits slightly changed. The creation of the dendrites was suppressed below $10 \mathrm{mAcm}^{-2}$ (Figure 8) and their character changed from tree- to needle, carrot- like (Figure 9), which indicates the change of the deposition mechanism from purely diffusion controlled to mixed activation-diffusion controlled [27]. It was observed, that the electrodeposition from an electrolyte with $\mathrm{Sn}$ to Fe ratio of 1:1 follows normal deposition when samples with 19.84 at $\%$ of Fe were deposited at $40 \mathrm{mAcm}^{-2}$. Iron rich deposits $(54.84$ at $\%)$ were obtained from the electrolyte with an increased $\mathrm{Fe}$ content. Attempts to obtain homogeneous, smooth deposit were made by adding $1.6 \mathrm{mgL}^{-1} \mathrm{ABN}$ additive into the iron rich electrolyte. In our previous studies [15], we have shown that, due to the ABN adsorption on the cathode in the chloride electrolytes, it acts as a very effective inhibitor and grain refiner for $\mathrm{Sn}$. In the case of the Sn-Fe electrolyte, the presence of $1.6 \mathrm{mgL}^{-1}$ ABN significantly reduced the amount of dendrites on the Hull cell (Figure 8). On the other hand, in comparison to the iron rich electrolyte without $\mathrm{ABN}$, the ratio of $\mathrm{Sn}$ to $\mathrm{Fe}$ in both the dendrites and the layer increased (Figure 9). A possible explanation is that with the adsorption of the $\mathrm{ABN}$ on the cathode both the hydrogen evolution and the Fe reduction are suppressed. Nevertheless, the exact role of ABN in the Fe-Sn chloride based electrolyte could be a part of further investigations.

The results from the X-ray analyses of the electrodeposited layers are compatible 
with the findings from the ASVs. In all the studied electrolytes, three different phases were identified, namely: $\beta$-Sn and intermetallic phases $\mathrm{FeSn}_{2}$ and $\mathrm{Fe}_{5} \mathrm{Sn}_{3}$. The $\mathrm{FeSn}_{2}$ phase is antiferromagnetic [3] and it was already electrodeposited by Chisholm et al.[11]. On the other hand the $\mathrm{Fe}_{5} \mathrm{Sn}_{3}$ phase exhibits ferromagnetic properties and is present in the thermodynamic phase diagram at temperatures above $1000 \mathrm{~K}$ [3]. The presence of the $\mathrm{Fe}_{5} \mathrm{Sn}_{3}$ phase was not influenced by the concentration of $\mathrm{Fe}$ in the electrolyte nor by the presence of $\mathrm{ABN}$.

\section{Conclusion}

Due to their magnetic properties and low impact on human health and environment, Fe-Sn alloys are considered as one of the possible alternatives to nowadays used Fe based Ni, Co alloys. In the present work, the conditions for electrodeposition of Fe-Sn from a novel, green, ferrous chloride-based electrolyte were studied. It was observed, that due to the changing character of Sn complexes, the reduction potential of Sn depends on the electrolyte $\mathrm{pH}$, while the reduction potential of $\mathrm{Fe}$ is independent of the $\mathrm{pH}$ value. Considering this dependency, the initial $\mathrm{pH}$ value of the mixed Fe-Sn electrolyte with the value of 5.5 was chosen as an optimum $\mathrm{pH}$ for $\mathrm{Fe}-\mathrm{Sn}$ electrodeposition.

Nevertheless, the $\mathrm{Fe}^{2+}$ based electrolyte with a $\mathrm{pH}$ of 5.5 was unstable, changing colour from light-yellow to orange- brownish, indicating the formation of ferric hydroxides. As a result the recorded current density transients were decreasing with each repetition of the measurement. The stability of the electrolyte was improved by decreasing the $\mathrm{pH}$ to a value of 2.8. At this $\mathrm{pH}$ value the results of ASVs indicated the possibility to deposit at least two different phases, one of them containing iron.

The samples deposited from the electrolyte with a $\mathrm{Sn}$ to Fe ratio of 1:1 at the $\mathrm{pH}$ of 2.8 showed a regular deposition of Fe-Sn. At $40 \mathrm{mAcm}^{-2}$ a deposit with $19.84 \mathrm{at} \%$ of 
Fe were obtained. With the reduction of Sn concentration in the electrolyte, the content of $\mathrm{Fe}$ in the deposit increased to $54.84 \mathrm{at} \%$. XRD results of the electrodeposited samples were compatible with ASVs. In both deposits the following phases were detected: $\beta$-Sn, and the intermetallics $\mathrm{FeSn}_{2}$ and $\mathrm{Fe}_{5} \mathrm{Sn}_{3}$. The $\mathrm{Fe}_{5} \mathrm{Sn}_{3}$ has a hexagonal structure and exhibits ferromagnetic properties and therefore, it is interesting for further investigation.

The Fe-Sn electrodeposition exhibits a complex interdependence of concentration, $\mathrm{pH}$ and deposition potentials. More detailed investigations of the Fe-Sn deposition mechanism could be performed in follow up studies.

Acknowledgements

This work was supported by the SELECTA (No. 642642) H2020-MSCA-ITN-2014 project. Authors would like to acknowledge Veronika Grman (Hirtenberger Engineering Surfaces) for performing SEM/EDX analyses and Werner Artner (X-ray Center, Vienna University of Technology) for the XRD analyses. 
1. Izaki, M. Electrodeposition og Iron and Iron alloys. In Modern electroplating; 2011; pp. 309-326 ISBN 1118063147.

2. https://echa.europa.eu/candidate-listtable?p_p_id $=$ disslists_WAR_disslistsportlet\&p_p_lifecycle $=1 \& p \_p \_s t a t e=$ norm al\&p_p_mode $=$ view\&p_p_col_id $=$ column$1 \& p \_p \_c o l \_p o s=2 \& p \_p \_c o l \_c o u n t=3 \&$ disslists_WAR_disslistsportlet_javax.po rtlet.action $=$ searchDissListsNo Accessible on 18.7.2019.

3. Giefers, H.; Nicol, M. High pressure X-ray diffraction study of all Fe-Sn intermetallic compounds and one Fe-Sn solid solution. Journal of Alloys and Compounds 2006, 422, 132-144, doi:10.1016/j.jallcom.2005.11.061.

4. Xiaowei, Zuo; Engang, W.; Huan, H.; Lin, Z.; Jicheng He Magnetic properties of $\mathrm{Fe}-49 \% \mathrm{Sn}$ monotectic alloys solidified under a high magnetic field. Journal of Alloys and Compounds 2010, 492, 621-624.

5. $\quad$ Sales, B. C.; Saparov, B.; McGuire, M. A.; Singh, D. J.; Parker, D. S. Ferromagnetism of Fe3Sn and alloys. Scientific Reports 2014, 4, 1-7, doi:10.1038/srep07024.

6. $\quad$ El-Sharif, M.; Chisholm, C. U.; Kuzmann, E.; Sziráki, L.; Stichleutner, S.; Homonnay, Z.; Süvegh, K.; Vértes, a. The structure and composition of novel electrodeposited $\mathrm{Sn}-\mathrm{Fe}$ and $\mathrm{Sn}-\mathrm{Co}-\mathrm{Fe}$ alloys from a flow circulation cell system. Hyperfine Interactions 2009, 192, 1-12, doi:10.1007/s10751-009-9940-9.

7. Yelsukov, E. P.; Voronina, E. V; Konygin, G. N.; Barinov, V. A.; Godovikov, S. K.; Dorofeev, G. A.; Zagainov, A. V Structure and magnetic properties of FeSnx alloys obtained by mechanical milling. Journal of Magnetism and Magnetic Materials 1997, 166, 334-348.

8. System, I. I. T. S. Mechanically Alloyed Sn-Fe ( -C ) Powders as Anode Materials for Li-Ion Batteries. 1999, 146, 414-422.

9. Dionisio, P. H. Vasquez, A. Hallouche, B. Mosca Jr., D. H. Teixeira, S. R. Schreiner, W. H. Structural and Magnetic properties of iron-tin thin films. Thin Solid Films 1992, 152-155, doi:10.4028/www.scientific.net/SSP.233-234.666.

10. Haftek, E.; Tan, M.; Barnard, J. A. Microstructure and magnetic properties of ferromagnetic Fe-Sn alloy thin films. Ultramicroscopy 1992, 47, 400-407, doi:10.1016/0304-3991(92)90171-F.

11. Chisholm, C. U.; El-Sharif; Kuzmann, E.; Stichleutner, S.; Homonnay, Z.; Vertes, a. Electrodeposition of Sn-Fe alloys using gluconate electrolytes and Xray diffractometry and M??ssbauer studies of the deposits. Materials Chemistry and Physics 2010, 120, 558-565, doi:10.1016/j.matchemphys.2009.12.001.

12. Mrkonjić Zajkoska, S.; Dobročka, E.; Hansal, S.; Mann, R.; Hansal, W. E. G.; Kautek, W. Tartrate-Based Electrolyte for Electrodeposition of Fe-Sn Alloys. Coatings 2019, 9, 313, doi:10.3390/coatings9050313.

13. Petter, G. J. Visual MINDTEQ 3.1 2014.

14. Hyperquad Simulation and Speciation software.

15. Zajkoska, S.; Mulone, A.; Hansal, W.; Klement, U.; Mann, R.; Kautek, W. Alkoxylated $\beta$-Naphthol as an Additive for Tin Plating from Chloride and Methane Sulfonic Acid Electrolytes. Coatings 2018, 8, 79, doi:10.3390/coatings8020079.

16. Nohse, W. The Hull cell; Robert Draper LTD: Teddington, 1966;

17. Lowenheim, F. A. Electroplating; Technical Reference Publications LTD, 1995;

18. Šeruga, M.; Metikoš-Hukovič, M. Passivation of tin in citrate buffer solution. Electrochimica Acta 1992, 334, 223-240.

19. Tselesh, A. S. Anodic behaviour of tin in citrate solutions: The IR and XPS study 
on the composition of the passive layer. Thin Solid Films 2008, 516, 6253-6260, doi:10.1016/j.tsf.2007.11.118.

20. Brenner, A. Electrodeposition of alloys, Principles and Practice, Volume I; Academic Press, London, 1963;

21. Bard, A. J. .; Parsons, R.; Jordan, J. Standard potentials in aqueous solution; 1st ed.; CRC Press, 1985;

22. Silva, A. M. N.; Kong, X.; Parkin, M. C.; Cammack, R.; Hider, R. C. Iron(iii) citrate speciation in aqueous solution. Dalton Transactions 2009, 8616-8625, doi:10.1039/b910970f.

23. Pham, A. N.; Waite, T. D. Oxygenation of Fe(II) in the presence of citrate in aqueous solutions at $\mathrm{pH} 6.0-8.0$ and $25^{\circ} \mathrm{C}$ : Interpretation from an $\mathrm{Fe}(\mathrm{II}) /$ citrate speciation perspective. Journal of Physical Chemistry A 2008, 112, 643-651.

24. Jovic, V. D.; Zejnilovic, R. M.; Despic, A. .; Stevanovic, J. S. Characterization of electrochemically formed thin layers of binary alloys by linear sweep voltamemetry. Journal of Applied Electrochemistry 1988, 18, 511-520, doi:10.1016/j.electacta.2012.12.053.

25. Seruga, M.; Mtikos-Hukovic, M. Passivation of tin in citrate buffer solutions. Journal of Electroanalytical Chemistry 1992, 334, 223-240, doi:10.1016/00220728(92)80574-N.

26. Morelock, R. J.; Sides, W. D.; Hu, Y.; Huang, Q. Electrochemical deposition and anodic stripping of $\mathrm{PdZn}$ bimetallic compound. Journal of Electroanalytical Chemistry 2018, 815, 8-15, doi:10.1016/j.jelechem.2018.03.003.

27. Popov, K. I.; Djokić, S. S.; Nikolić, N. D.; Jović, V. D. Morphology of Electrochemically and Chemically Deposited Metals; 2016; ISBN 978-3-31926071-6. 


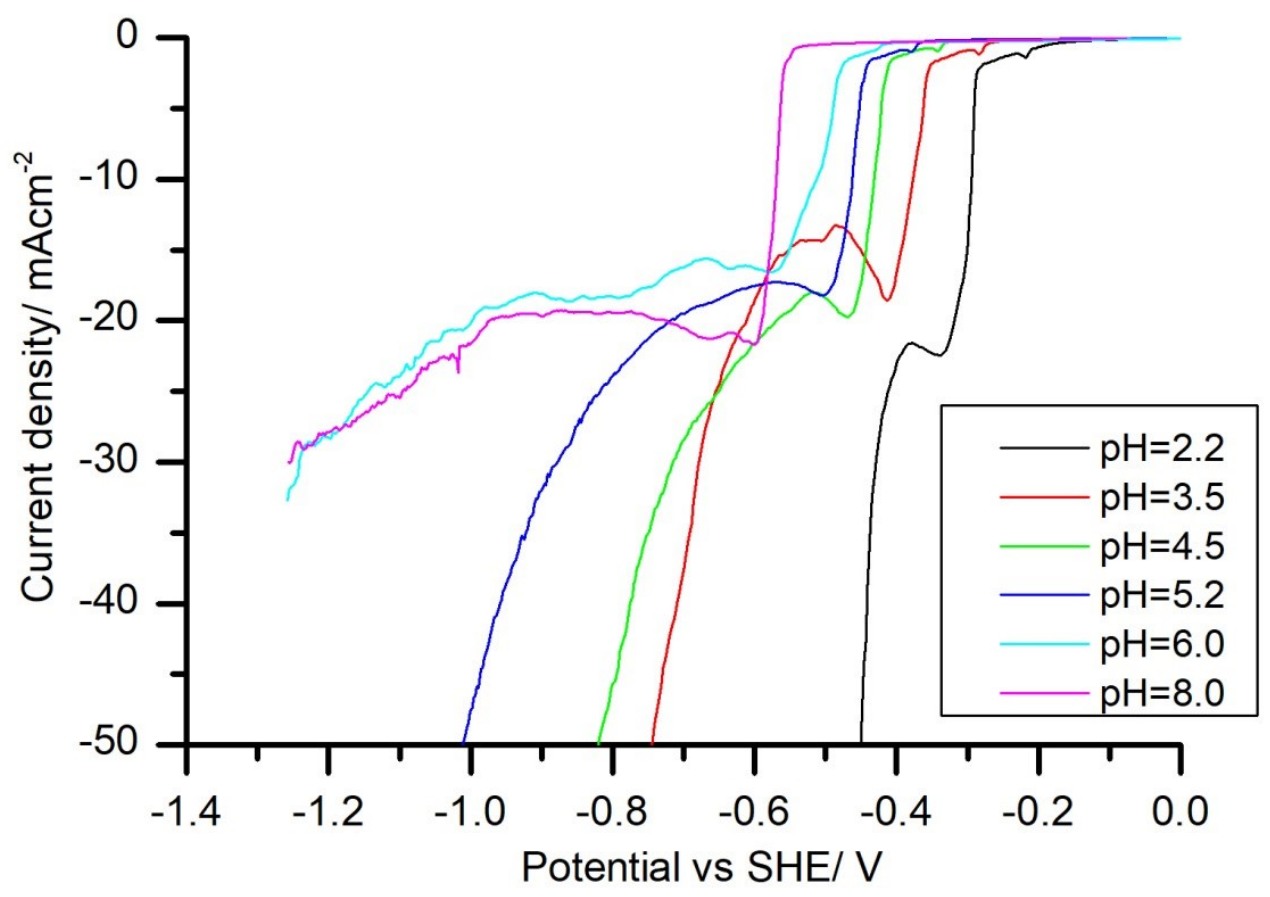

Figure 1: Dependence of the electrolyte $\mathrm{pH}$ on the cathodic polarisation behaviour of the $\mathrm{Sn}$ electrolyte. Measured with a scan rate of $5 \mathrm{mV} / \mathrm{s}$. 


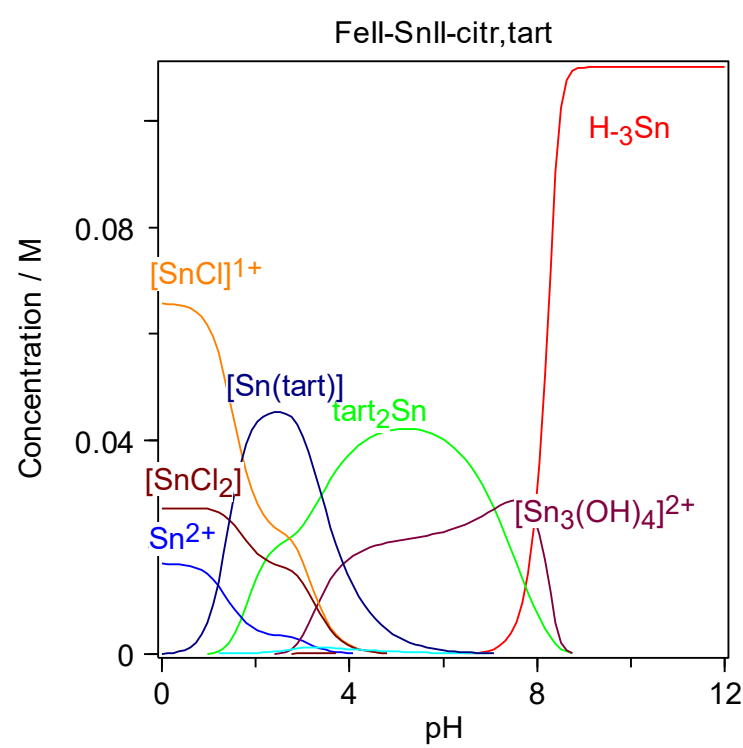

a)

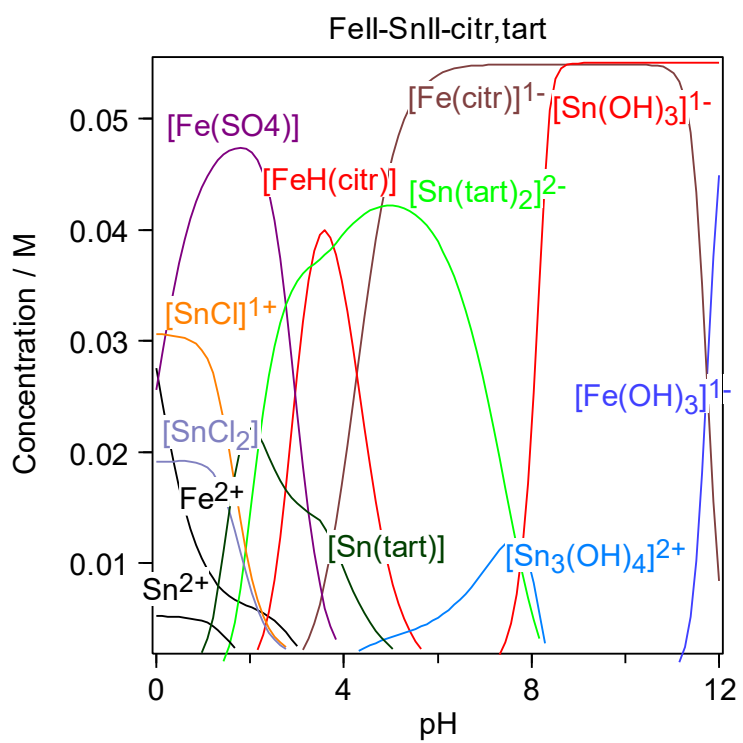

c)

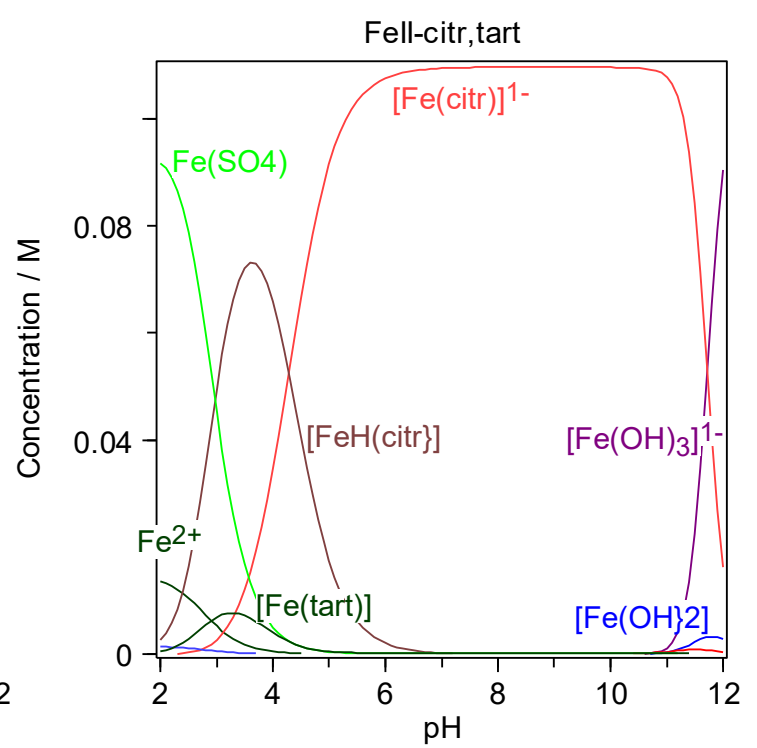

b)

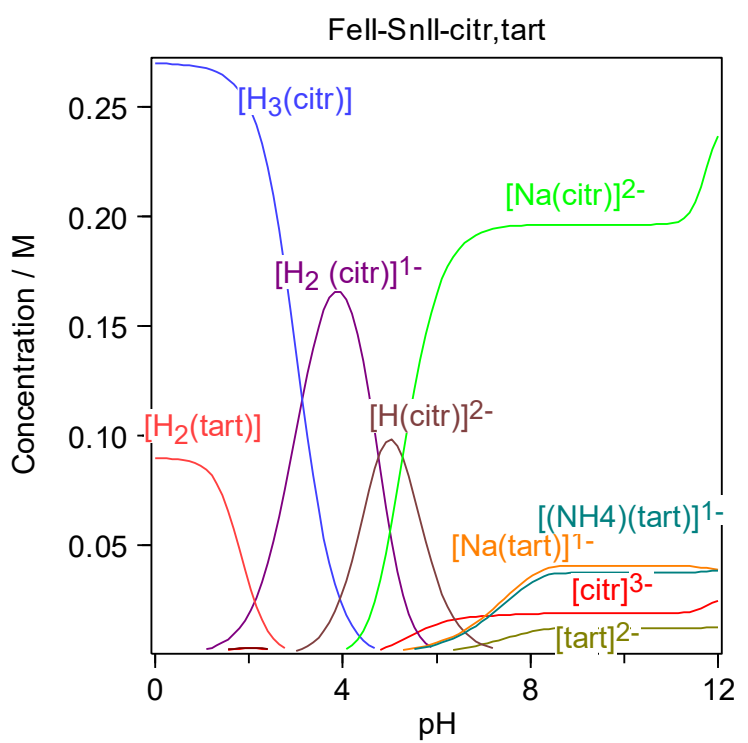

d)

Figure 2: Electrolytes speciations: a) 0,11 M Sn single metal b) $0.11 \mathrm{M} \mathrm{Fe}$ single metal c) mixed $\mathrm{Sn}-\mathrm{Fe}$ electrolyte with $\mathrm{Sn}$ : Fe ratio 1:1. Depicted are only $\mathrm{Sn}$ and Fe complexes. d) mixed $\mathrm{Sn}-\mathrm{Fe}$ electrolyte with $\mathrm{Sn}$ : Fe ratio 1:1. Depicted are only citrate and tartrate non-metal complexes. 


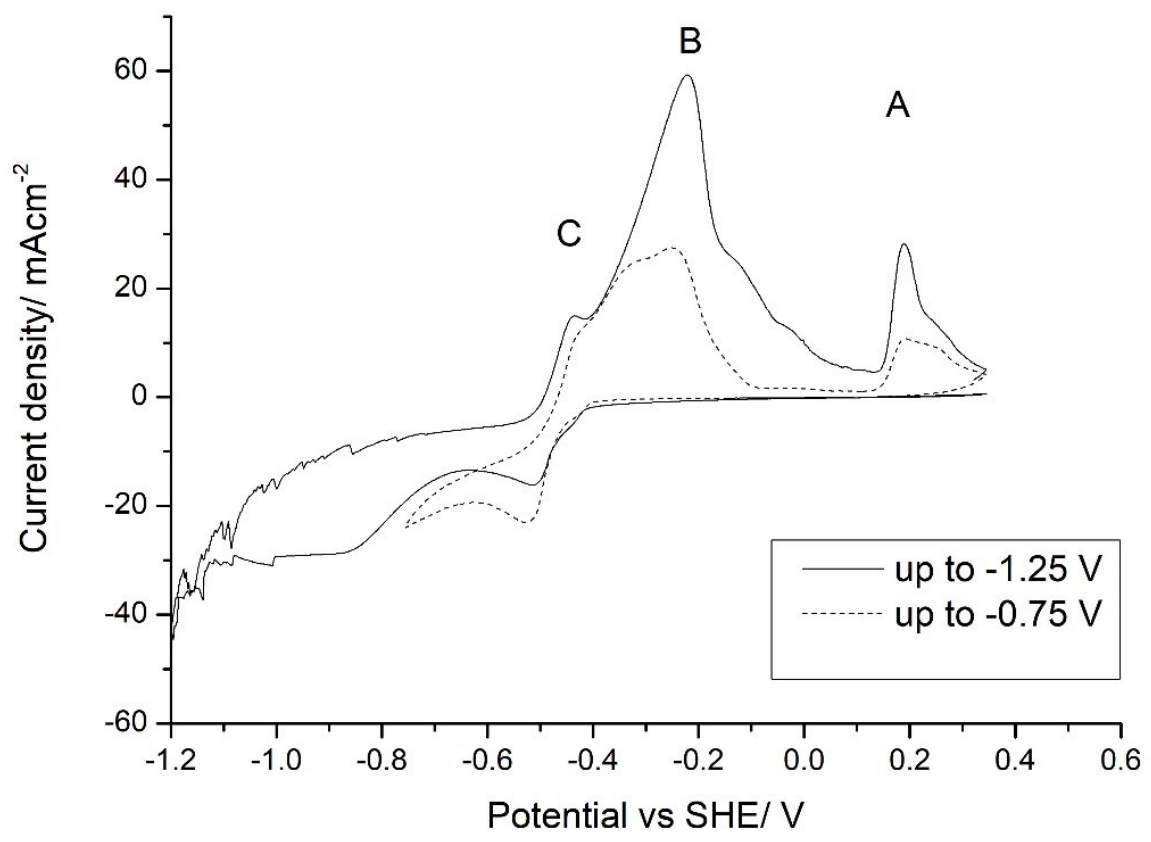

Figure 3: Anodic stripping voltammetries (ASV) measured in the $0.11 \mathrm{M} \mathrm{Sn}$ electrolyte, $\mathrm{pH}$ value of 5.2 with two different cathodic reverse potentials. 


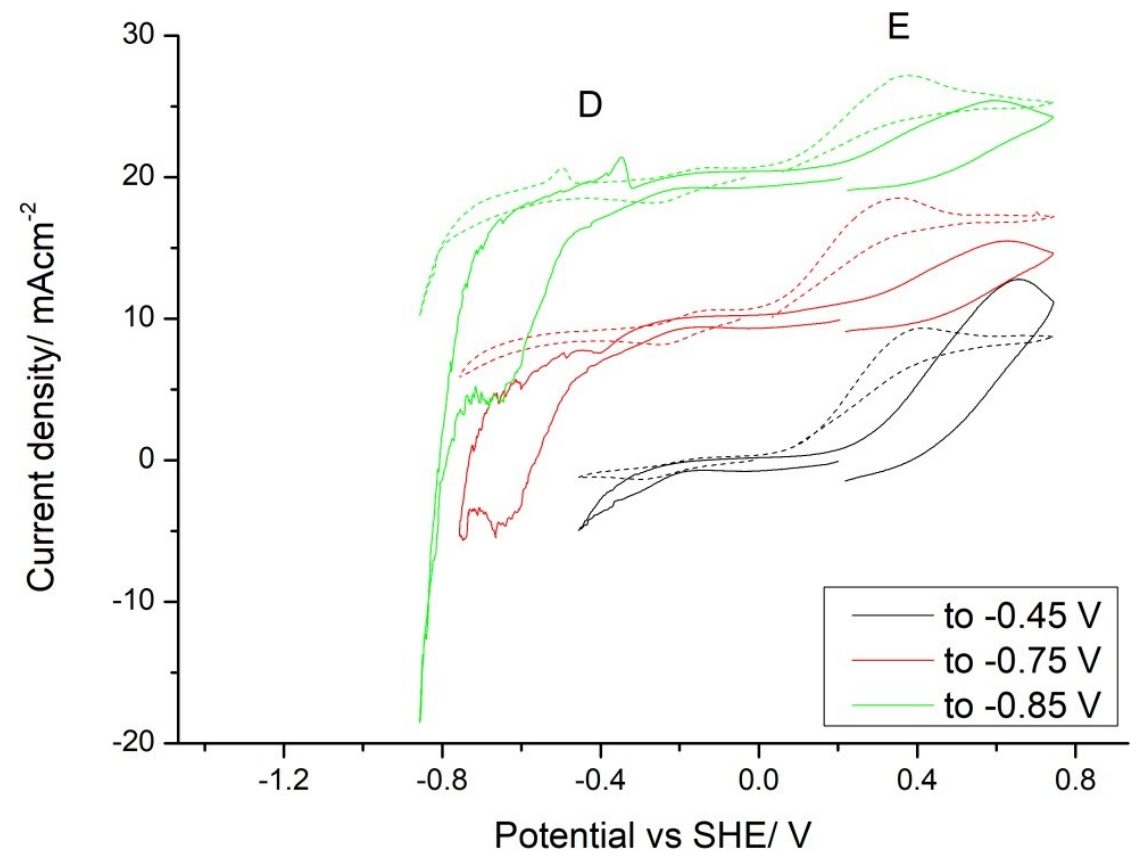

Figure 4: AVs with different cathodic reverse potential measured in the $0,11 \mathrm{M} \mathrm{Fe}$ electrolytes with the $\mathrm{pH}$ values of 6.0 (dashed) and 2.8 (full line). The anodic stripping peak D refers to the oxidation of Fe and was for the first time detected when the electrode was polarized cathodically up to $-0.85 \mathrm{~V}$ vs SHE. 

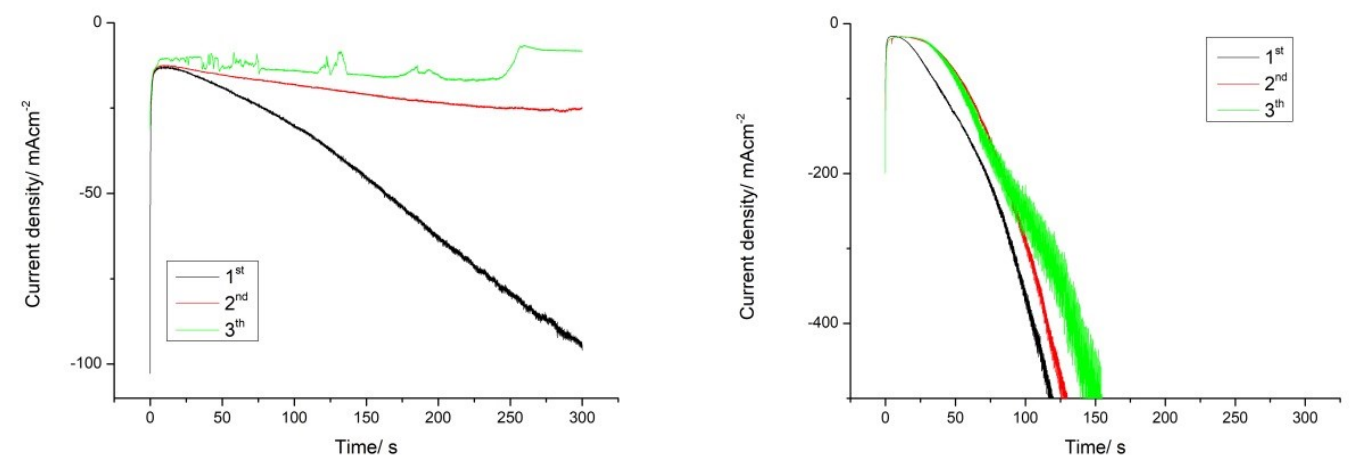

Figure 5: Current density transients recorded at the potential of $-0.75 \mathrm{~V}$ in the Fe-Sn electrolyte with Fe to $\mathrm{Sn}$ metal ratio 1:1 and $\mathrm{pH}$ value of 5.5 (left) and 2.8 (right). 


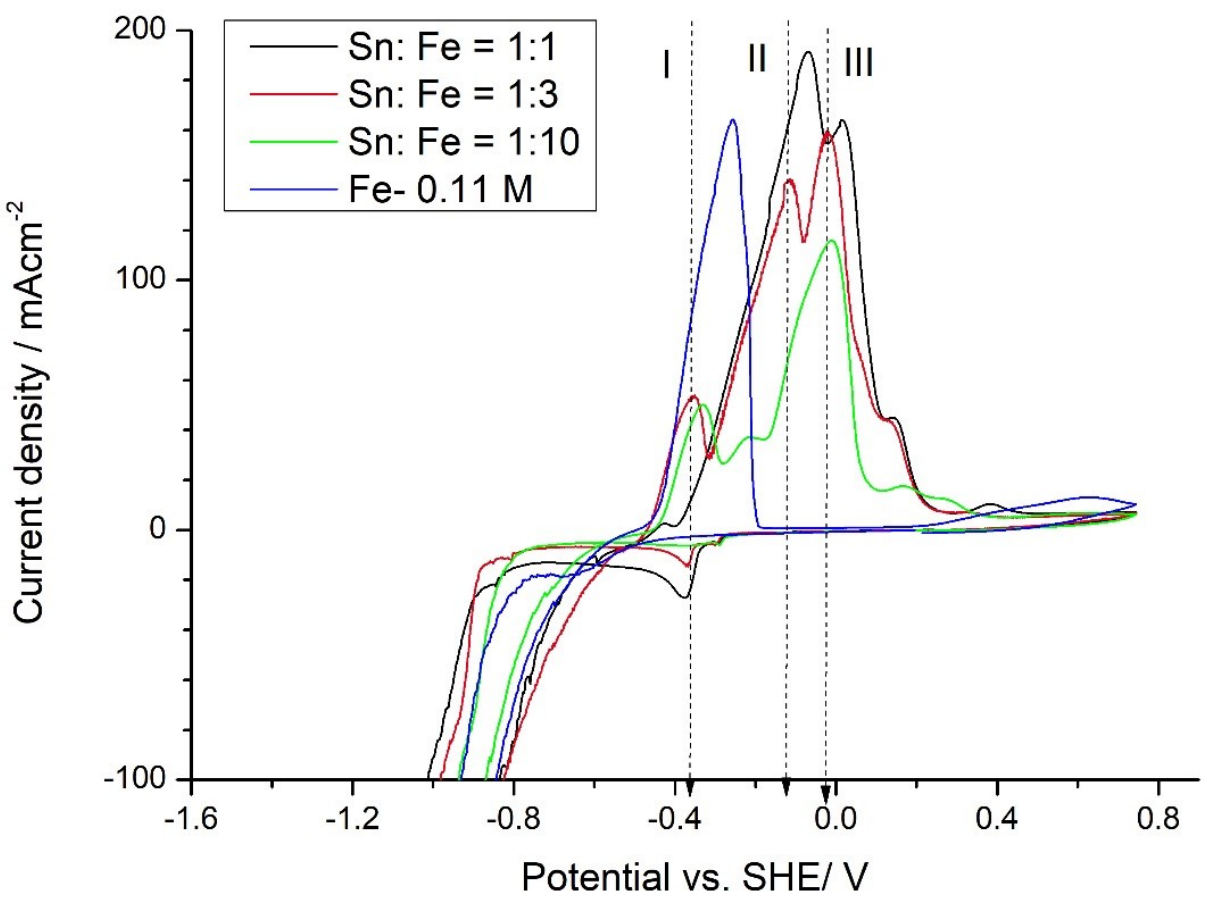

Figure 6: The influence of the $\mathrm{Fe}$ and $\mathrm{Sn}$ ion ratio in the electrolyte $(\mathrm{pH} 2.8)$ on the ASVs in comparison to the single metal Fe electrolyte. The Fe-Sn layers were polarized during the cathodic sweep up to the $-1.25 \mathrm{~V}$ vs SHE. Consequently, anodic stripping up to $+0.75 \mathrm{~V}$ vs SHE with the scan rate of $50 \mathrm{mV} / \mathrm{s}$ was performed. The vertical lines are marking the potentials of the stripping peaks in the electrolyte with $\mathrm{Sn}$ to Fe ratio 1:3 and cathodic reverse potential of $-1.25 \mathrm{~V}$. 


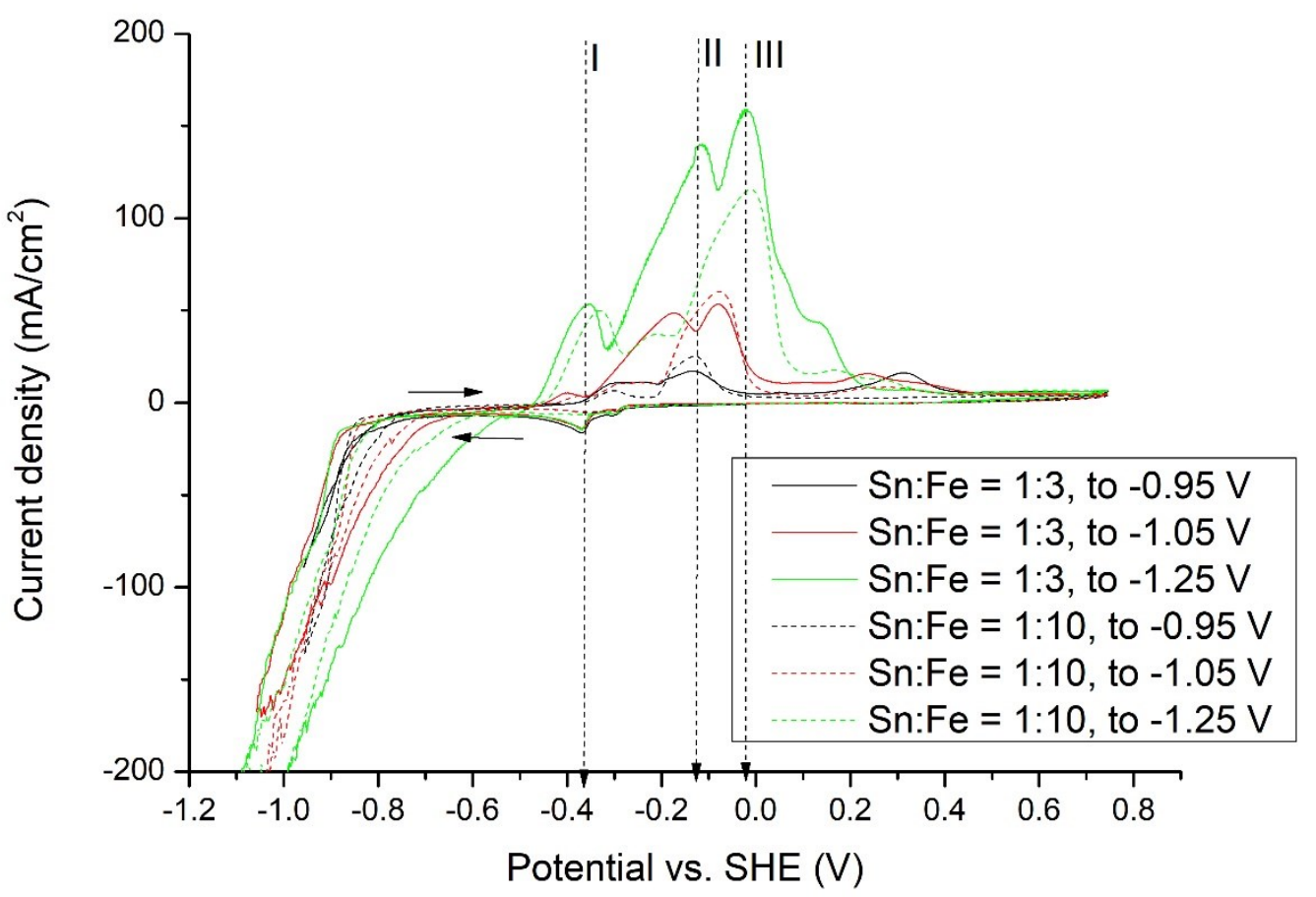

Figure 7: The influence of the cathodic reverse potential on the ASVs in the electrolytes with the electrolytes with the Sn:Fe ratio in the electrolyte 1:3 and 1:10. The vertical lines are marking the potentials of the stripping peaks in the electrolyte with $\mathrm{Sn}$ to Fe ratio 1:3 and cathodic reverse potential of $-1.25 \mathrm{~V}$. 

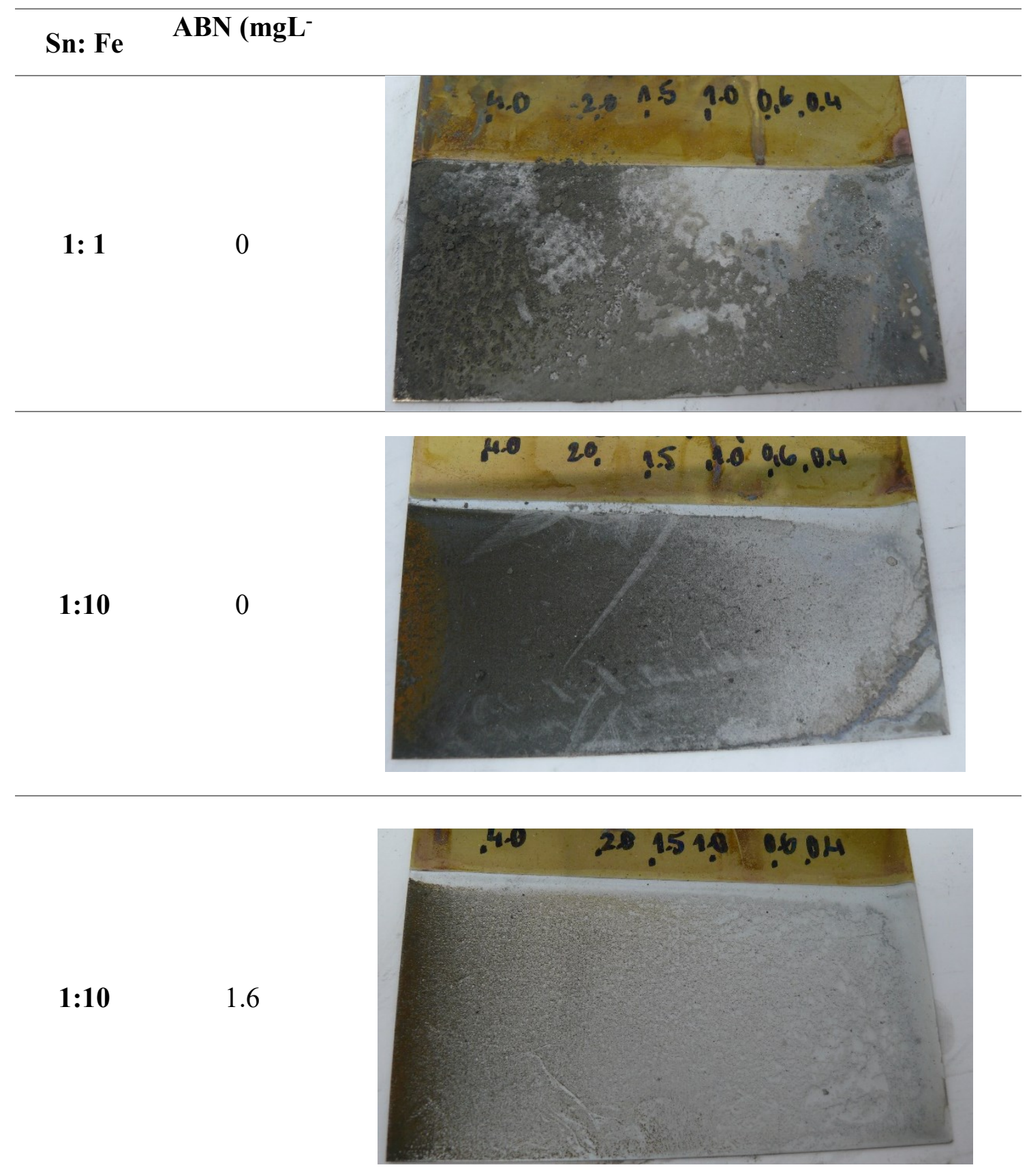

Figure 8: Influence of the electrolyte composition on the character of the Hull cell deposits. Nominal current densities on the Hull cells are marked in the $\mathrm{Adm}^{-2}$. 


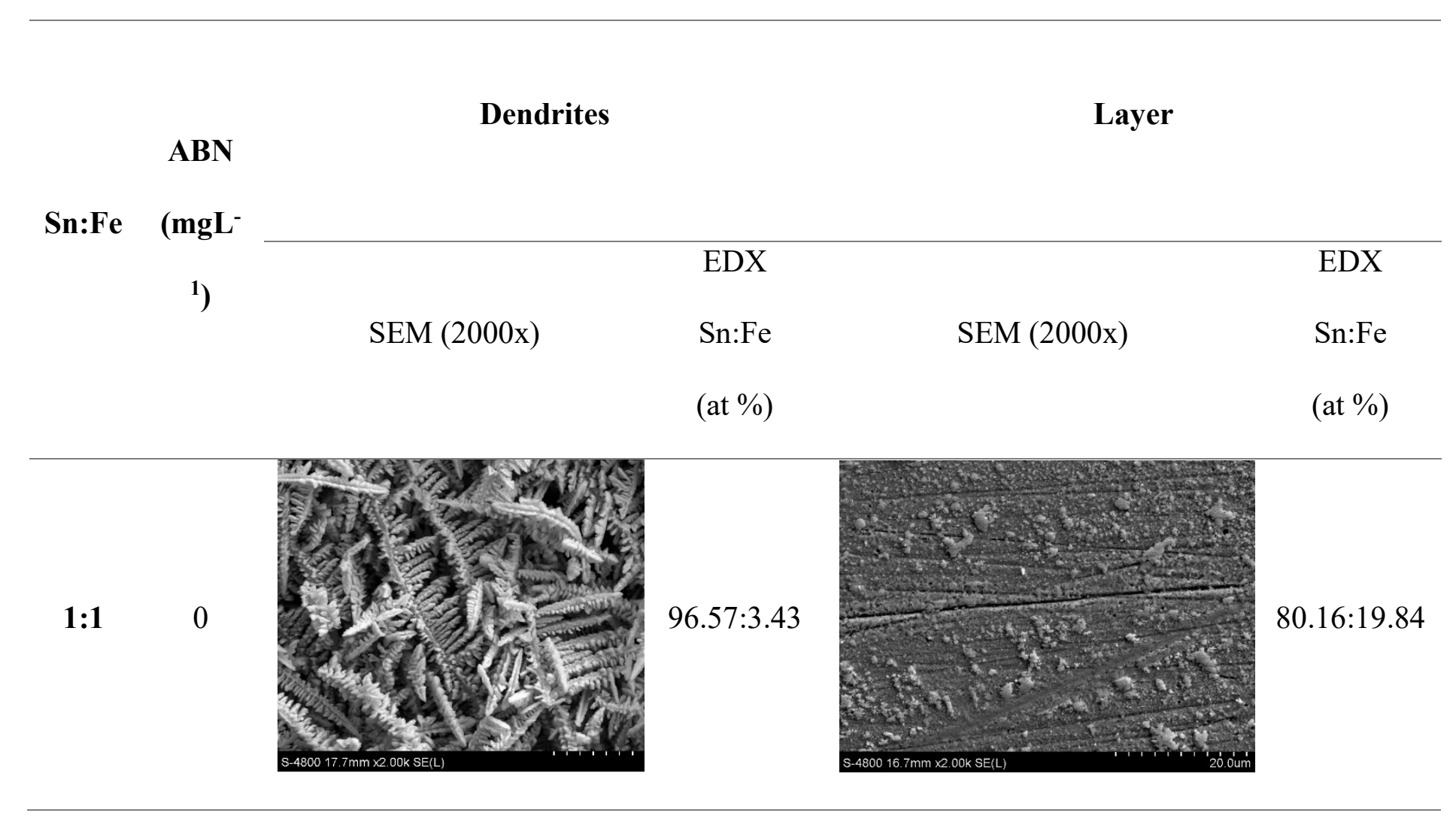




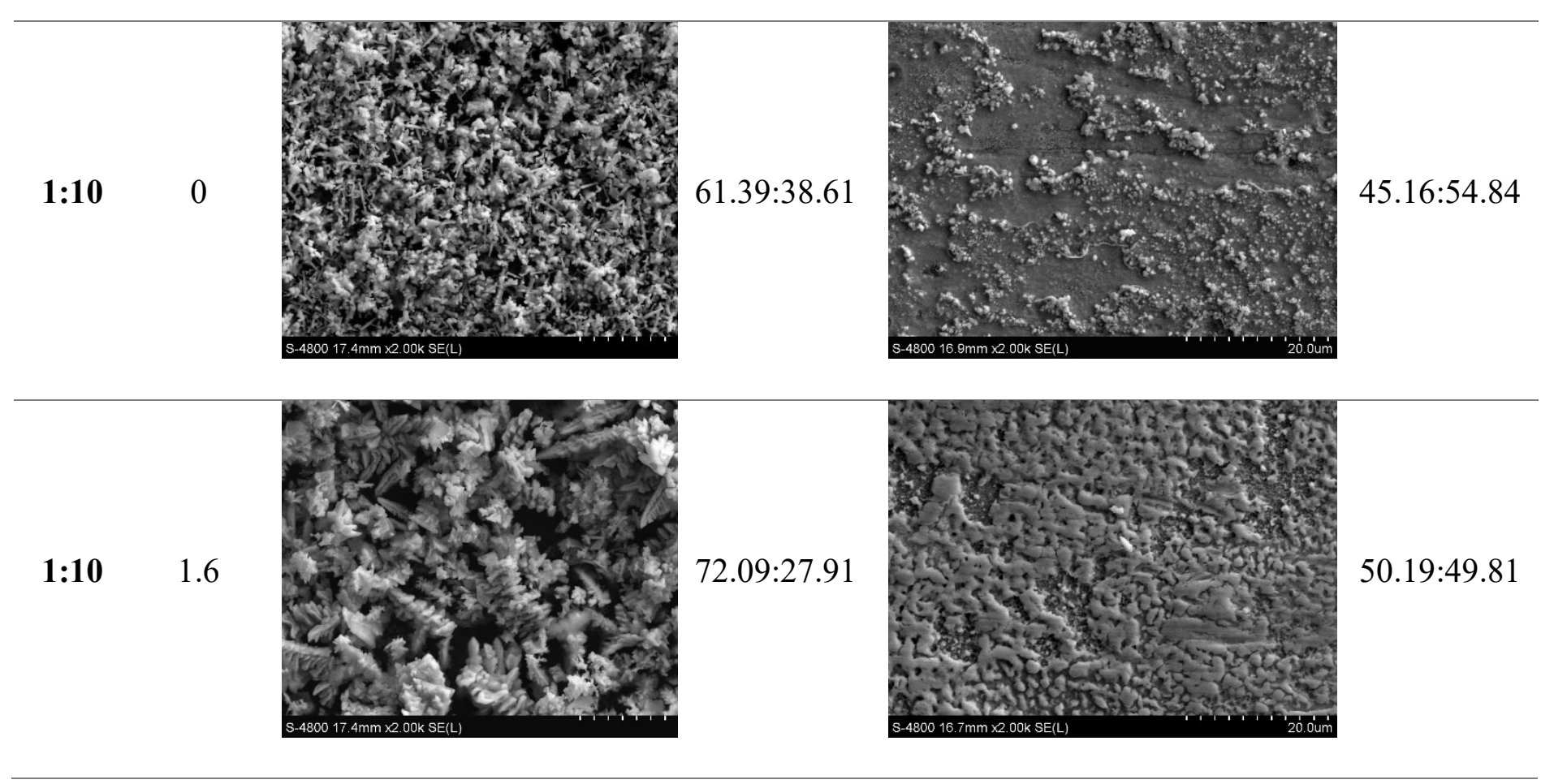

Figure 9: Topography images and stoichiometry of the electrodeposited dendrites and layers on the Hull cells at the nominal current density value of $40 \mathrm{mAcm}^{-2}$. 


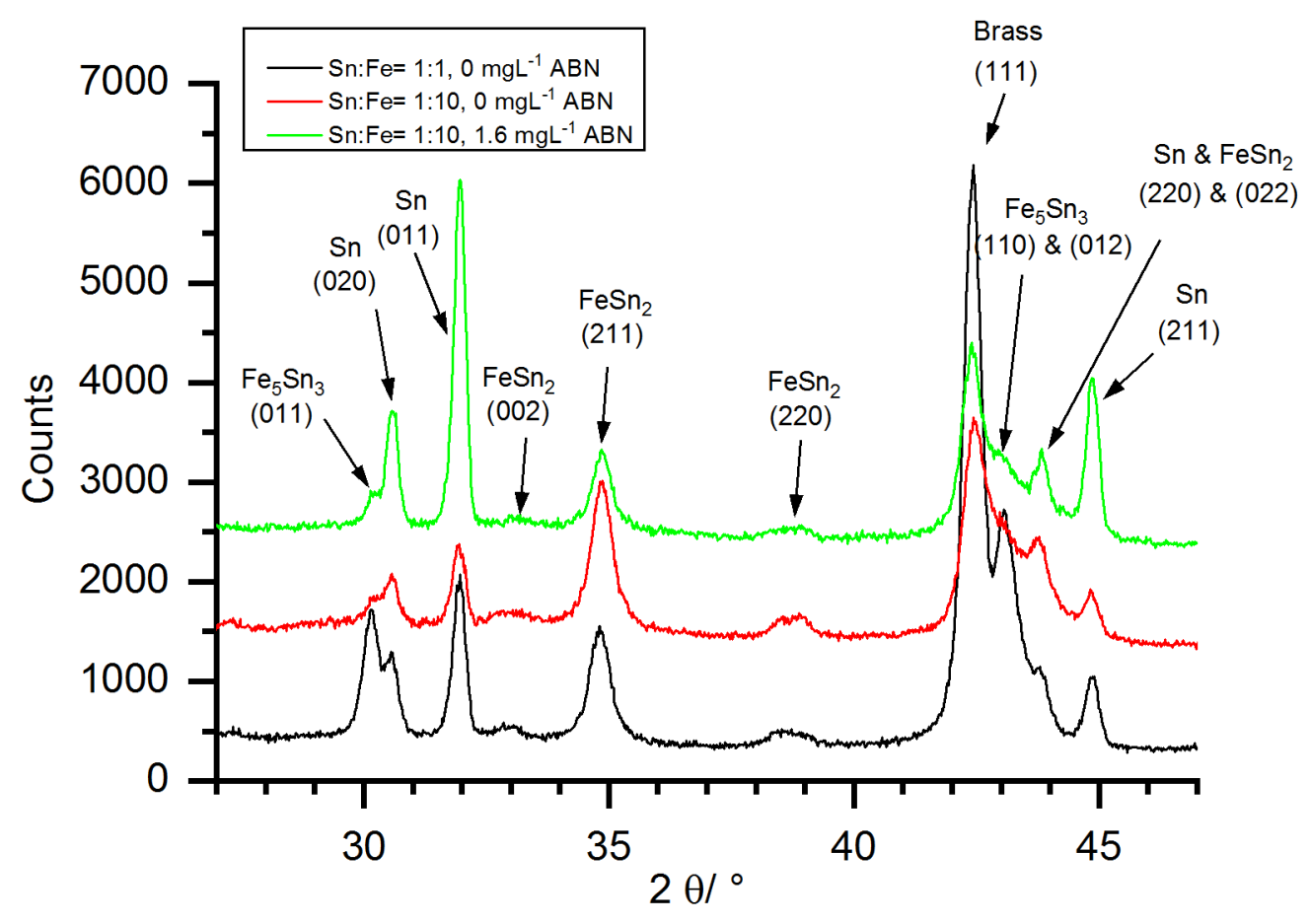

Figure 10: XRD diffractograms of the electrodeposited Sn-Fe from the electrolytes with Sn to Fe ions ratio 1:1 and 1:10, with and without the presence of $A B N$. The samples were obtained from a Hull cell deposition at a nominal current density value of $40 \mathrm{mAcm}^{-}$ 2 . 